
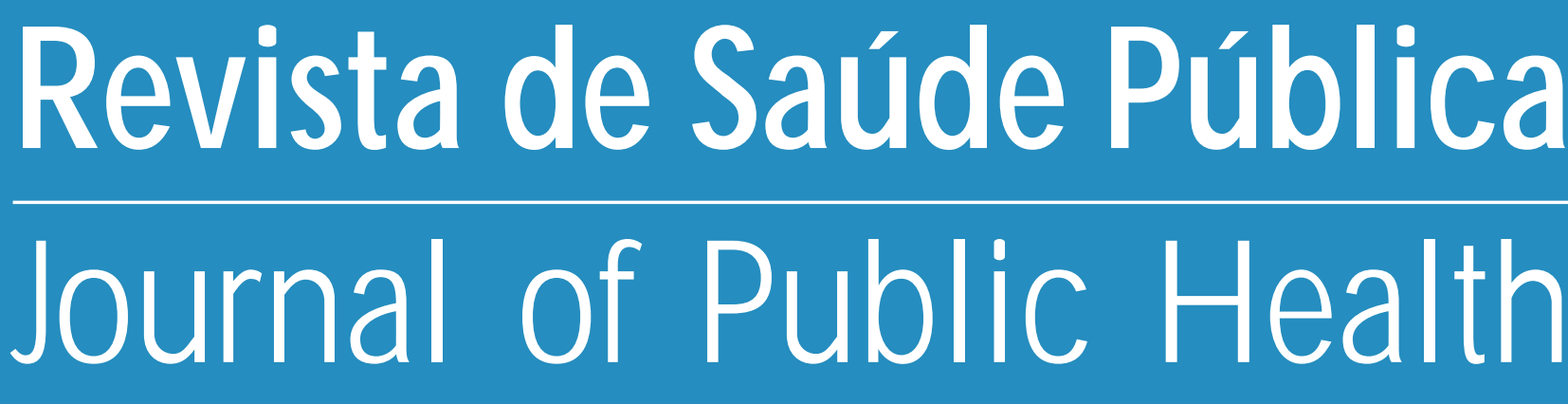

\title{
Análise de tratamento anti-rábico humano pós-exposição em região da Grande São Paulo, Brasil
}

Analysis of human anti rabic post exposure treatment in an urban region of Southeastern Brazil

Rita C. M. Garcia, Silvio A . Vasconcellos, Sidnei M. Sakamoto e André C. Lopez

Secretaria Municipal de Saúde de O sasco. Divisão de Controle de Zoonoses. O sasco, SP - Brasil (RCMG); Departamento de Medicina Veterinária Preventiva e Saúde Animal da Faculdade de Medicina Veterinária e Zootecnia da Universidade de São Paulo. São Paulo, SP - Brasil (SAV, $S M S, A C L)$ 


\title{
Análise de tratamento anti-rábico humano pós-exposição em região da Grande São Paulo, Brasil*
}

\section{Analysis of human anti rabic post exposure treatment in an urban region of Southeastern Brazil}

\author{
Rita C. M. G arcia, Silvio A . Vasconcellos, Sidnei M. Sakamoto e André C. Lopez \\ Secretaria Municipal de Saúde de O sasco. Divisão de Controle de Zoonoses. O sasco, SP - Brasil \\ $(R C M G) ;$ Departamento de Medicina Veterinária Preventiva e Saúde Animal da Faculdade de \\ Medicina Veterinária e Zootecnia da Universidade de São Paulo. São Paulo, SP - Brasil (SAV, \\ $S M S, A C L)$
}

\section{Descritores}

Raiva, terapia.

Vírus da raiva, imunologia.

\section{Resumo}

\section{Introdução}

O tratamento de seres humanos expostos ao risco de infecção pelo vírus rábico ainda pode incluir a ocorrência de reações pós-vacinais indesejáveis, tanto de ordem local como geral. A análise sistemática dos informes epidemiológicos de pacientes submetidos a este tipo de tratamento poderá oferecer subsídios para a modificação desta situação. Foram analisados os registros de tratamento dessa zoonose visando à melhoria do seu controle.

\section{Métodos}

Foram analisadas através do programa Epi Info as fichas de investigação epidemiológica da raiva de 8.758 habitantes do Município de Osasco, SP (Brasil), atendidos no período de 1984 a 1994. A vacina utilizada foi do tipo Fuenzalida \& Palacios.

\section{Resultados}

Constatou-se a existência de maior risco de exposição para os indivíduos do sexo masculino, com cinco a nove anos de idade. As agressões ocorreram com maior freqüência no domicílio da vítima e os cães foram os principais responsáveis. Dos cães e gatos envolvidos, respectivamente 51,0\% e 73,2\% não haviam sido imunizados contra a raiva. Nos pacientes com até nove anos de idade as localizações de lesão mais frequientes foram: cabeça $(36,6 \%)$ e membros superiores $(35,1 \%)$; quando a faixa etária ultrapassava os nove anos as áreas mais acometidas foram membros superiores $(45,8 \%)$ e membros inferiores $(43,7 \%)$. Dos pacientes analisados, 26,5\% já haviam recebido vacinação anti-rábica anterior e $90,7 \%$ procurou a orientação médica em até cinco dias da agressão. Para $41,9 \%$ foi prescrita unicamente a vacinação e para $0,05 \%$ a soro-vacinação.

\section{Correspondência para/Correspondence to:}

Rita de Cássia Maria Garcia

Rua Prof. Astolfo Tavares Paes, 86, 24A.

05352- 070 São Paulo-SP, Brasil

E-mail: rgarcia@plugnet.com.br
*Baseado na dissertação de mestrado apresentada à Faculdade de Medicina Veterinária e Zootecnia da Universidade de São Paulo, 1996. Apresentado no Congresso Brasileiro de Medicina Veterinária, Gramado/RS, 1997.

Edição subvencionada pela FAPESP (Processo n 98/13915).

Recebido em 16.2.1998. Reapresentado em 22.8.1998. Aprovado em 23.9.1998. 


\section{Conclusões}

Houve $11,7 \%$ de abandonos a tratamentos e 51,3\% foram dispensados do mesmo em função da observação animal. Dos pacientes tratados com vacina ou sorovacinação houve $0,25 \%$ de acidentes pós-vacinais, dos quais $0,3 \%$ do tipo neurológico. Os meses de março, julho, agosto e setembro foram os de maior procura.

\section{Keywords}

Rabies, therapy.

Rabies virus, imunology.

\begin{abstract}

\section{Introduction}

The treatment of human beings with risk of exposure to rabies virus infection still presents some cases of undesirable post treatment reactions. The knowledge resulting from the regular analysis of the epidemiological features associated with these practices would minimize the occurrence of these troubles.
\end{abstract}

\section{Methods}

The records of the treatment of 8,758 human anti-rabies cases performed in Osasco City, S. Paulo, Brazil between 1984 and 1994 with Fuenzalida \& Palacios vaccine and/or anti-rabies serum produced in equines were analysed by Epi Info program.

\section{Results}

It was found that the higher risk of exposure was for male children of from five to nine years of age. The most frequent scene of aggression was the victim's own house. Dogs were responsible for most of the accidents (62.8\%); the majority of dogs and cats involved had not been immunized against rabies $(51.0 \%$ of dogs and $73.2 \%$ of cats). Most people aged nine or under were attacked in the head (36.6\%), followed by the upper limbs (35.1\%); above this age the part of the body most frequently hurt was the upper (45.8\%) and lower limbs (43.7\%); 26.5\% of patients had already been vaccinated against rabies at least once in their lifetime; 90.7\% of them sought medical care within five days, anti-rabies treatment was prescribed for $41.9 \%$ of them.

\section{Conclusions}

Post vaccinal reactions were observed in $0.25 \%$ of the patients $0.3 \%$ of which were of neurological; $80.1 \%$ of the dogs and $58.4 \%$ of the cats involved coere kept under observation. The months of March, July, August and September presented the highest aggression rates.

\section{INTRO DUÇÃO}

O tratamento dos seres humanos expostos ao vírus da raiva pela aplicação de prolongado processo de imunização, com posologia variável de acordo com a gravidade das lesões, ainda é a única conduta capaz de prevenir a manifestação da doença ${ }^{1,3,17,18}$.

A análise de uma série histórica de tratamentos anti-rábicos pós-exposição, efetuados em uma dada região, permite que os serviços de vigilância epidemiológica locais se auto avaliem e se aprimorem. Diversos inquéritos sobre essa temática já foram realizados no Brasil ${ }^{6,8,11}$ e no exterior ${ }^{7,16}$. As conclusões obtidas são restritas aos respectivos períodos analisados e às condições técnicas e socioeconômico-culturais vigentes em cada situação.
Os esforços das autoridades de saúde pública relativos ao controle da raiva, em áreas metropolitanas brasileiras, têm determinado grande redução dos casos de raiva humana e animal ${ }^{15}$. Nessas localidades não tem ocorrido a redução proporcional no número de seres humanos submetidos a tratamentos antirábicos pós-exposição ${ }^{6,15}$. A despeito da grande evolução observada, nos últimos anos, em termos do aprimoramento das técnicas de produção e de aplicação das vacinas anti-rábicas de uso humano, essas práticas ainda encerram considerável risco da ocorrência de complicações pós-vacinais, tanto de ordem local como geral ${ }^{1,2,3,18}$

A análise sistemática dos informes epidemiológicos relacionados aos tratamentos anti-rábicos instituídos poderá oferecer elementos que modifiquem esta situação. 
Deste modo o presente estudo tem por objetivo analisar os registros dos tratamento anti-rábicos pósexposição efetuados em habitantes do Município de Osasco, no período de 1984 a 1994 e oferecer subsídios para o aprimoramento dos serviços de controle da referia zoonose em nível local.

\section{MÉTO DOS}

O Município de Osasco localiza-se na região oeste da Grande São Paulo, sudeste do Brasil. Possui 69,2 km² de extensão geográfica, totalmente urbanizados e no ano de 1995 apresentava a estimativa populacional de 602.626 habitantes ${ }^{10}$. O último caso de raiva humana desse município foi registrado em 1979. No período compreendido entre 1984 a 1994 houve, anualmente, de 599 a 1.069 seres humanos agredidos por animais.

A Prefeitura de Osasco, através da Divisão de Controle de Zoonoses e Animais Peçonhentos, realiza campanhas anuais de vacinação das populações canina e felina, mas não executa atividade de controle da população animal e nem diagnóstico laboratorial de rotina para detecção de vírus rábico circulante. Possui Serviço de Profilaxia da Raiva Humana centralizado no Pronto Socorro Central, onde são atendidos todos os pacientes agredidos por animais. A Vigilância Epidemiológica do Município de Osasco acompanha todos os casos de agressões e, se necessário, procede observação animal domiciliar.

Foram levantadas 8.758 fichas de habitantes do $\mathrm{Mu}-$ nicípio de Osasco que procuraram tratamento anti-rábico pós-exposição, no período de 1984 a 1994, as quais foram compiladas através do programa Epi Info ${ }^{4}$.

As fichas dos pacientes atendidos no período de 1984 a 1991 foram localizadas no Instituto Pasteur da Secretaria de Saúde do Estado de São Paulo; as correspondentes ao período de 1992 a 1994 foram obtidas no Serviço de Profilaxia da Raiva Humana do Município de Osasco.

O preenchimento original das fichas trabalhadas havia sido efetuado pelos funcionários do Serviço que incluíram: atendentes de enfermagem, agentes de saúde e médicos, sendo que estes últimos foram os responsáveis pela avaliação clínica e conduta preconizada.

Durante o período analisado houve alterações nos modelos de fichas empregadas e vigoraram duas normas técnicas: NT 26/81 12,13 , de 1984 a 1988 e NT $1 / 88^{14}$ de novembro de 1988 a 1994 . A vacina empregada foi sempre do tipo Fuenzalida \& Palácios ${ }^{5,15}$ e o soro hiperimune foi do tipo heterólogo, produzido em eqüinos ${ }^{15}$.

\section{RESU LTAD O $S$}

Das 8.758 fichas analisadas, a freqüência de campos não preenchidos foi muito elevada; dentre os aspectos com maior percentual de falhas no preenchimento (superior a 60,0\%) constaram: tipo de ob-

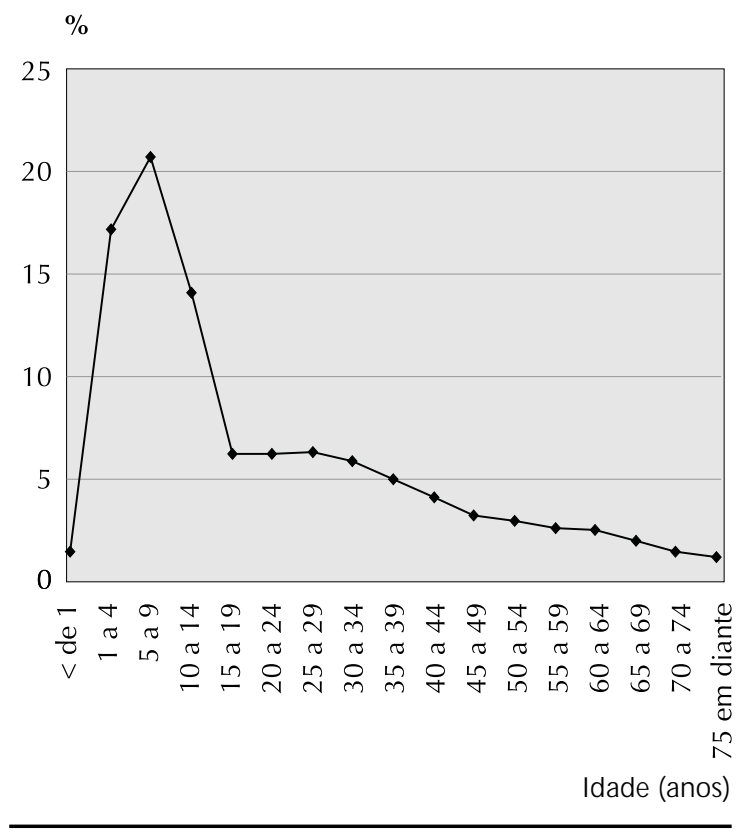

Figura 1 - Pacientes atendidos pelo Serviço de Profilaxia da Raiva da Secretatia Municipal de Saúde de O sasco ou pelo Instituto Pasteur de São Paulo, segundo a vaixa etária.

servação adotada, o resultado da observação do animal, o número de reforços vacinais aplicados, a evolução da vacinação, os acidentes pós-vacinais e o local da vacinação.

Os indivíduos mais freqüentemente expostos à agressões de animais foram da faixa etária compreendida entre um a 14 anos $(53,4 \% /$ Figura 1$)$. Dos 8.758 pacientes atendidos, $56,8 \%$, foram do sexo masculino. Dos menores de 14 anos (53,4\%), 61,2\% foram do sexo masculino e $37,3 \%$ do feminino. Dentre os maiores de 14 anos $(46,6 \%), 51,6 \%$ foram do sexo masculino e $46,4 \%$ do feminino.

A maior freqüência das agressões animais ocorreu no próprio domicílio dos pacientes $(46,8 \%)$ e em segundo lugar constaram as vias públicas $(22,3 \%)$. Os locais ignorados representaram $22,8 \%$ do total.

Os animais responsáveis pelas agressões em ordem decrescente de freqüência foram: cães $(52,3 \%)$, roedores $(6,3 \%)$, gatos $(4,8 \%)$, macacos $(0,8 \%)$; ignorados $(35,6 \%)$. Houve casos esporádicos envolvendo outros tipos de animais: morcegos $(n=5)$, eqüinos $(n=7)$, coelhos $(n=14)$, quati $(n=3)$, leão $(n=1)$, cabra $(n=1)$, tamanduá $(n=1)$, porco $(n=1)$. No relativo a condição de imunização anti-rábica constatou-se $42,1 \%$ de cães agressores de um total de 4,582; e de 13,4\% de gatos, de um total de 418 (Figura 2). 


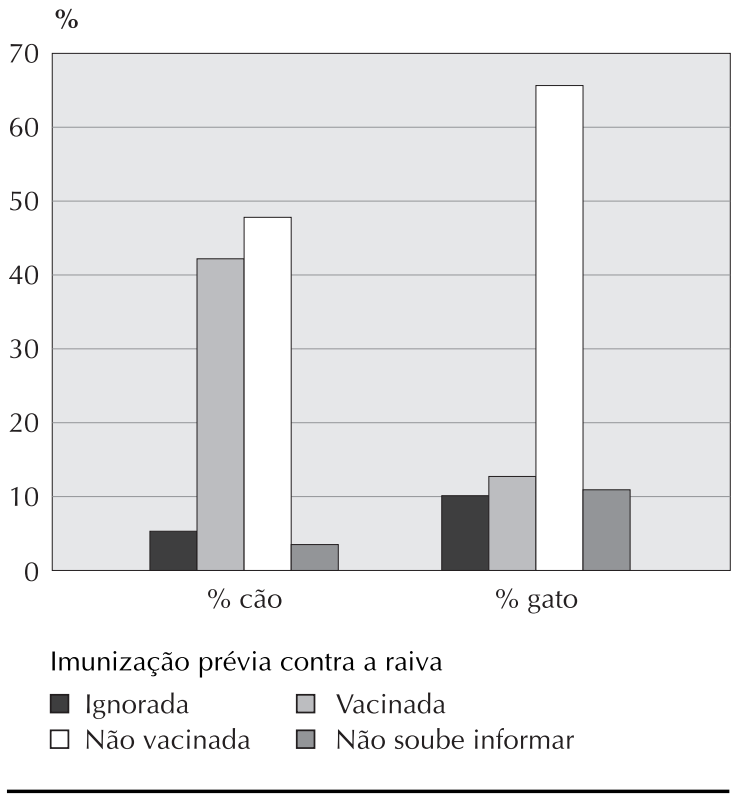

Figura 2 - Cães e gatos responsáveis por agressões a pacientes atendidos pelo Serviço de Profilaxia da Raiva da Secretaria M unicipal de Saúde de O sasco e pelo Instituto Pasteur de São Paulo, segundo o tipo de animal e consição de imunização prévia contra a raiva.

Quanto ao estado clínico dos animais agressores, $65,9 \%$ encontravam-se sadios no momento da agressão e em $21,1 \%$ o estado clínico do animal era desconhecido. A proporção de animais indicados como doentes foi de $1,6 \%$.

A mordedura e a arranhadura representaram, respectivamente, $91,6 \%$ e $3,1 \%$ do tipo de exposição nos casos analisados. As localizações de lesões foram: membros superiores $40,9 \%$; membros inferiores $37,2 \%$ e a cabeça $(19,4 \%)$. A Figura 3 apresenta a combinação das proporções das sedes de lesões com a faixa etária dos pacientes.

Dentre as condutas tomadas pelos pacientes, imediatamente após a ocorrência da agressão, a desinfeção dos ferimentos foi adotada em $83,1 \%$ das oportunidades.

A condição de já ter recebido tratamento antirábico anterior foi confirmada em $25,8 \%$ das ocasiões, em 71,4\% não houve tratamento anterior e em $2,8 \%$ a informação foi ignorada.

O intervalo de tempo decorrido entre o momento da agressão e a procura do tratamento anti-rábico esteve, em $88,6 \%$ das ocasiões, entre zero a cinco dias; em $6,8 \%$, entre seis a dez dias; mais do que 10 dias, $2,2 \%$ e mais que um ano, $0,5 \%$.

Quanto aos tipos de condutas adotadas constatou-se que $50,6 \%$ dos pacientes foram dispensados da vacinação devido a possibilidade da observação do animal agressor.; 30,7\% foram vacinados; em $10,6 \%$ houve vacinação e observação do animal agressor e em $5,9 \%$ houve a dispensa do tratamento.

As categorias registradas para a observação do animal agressor incluiu: ignorada $(82,6 \%)$; proprietário/vítima (16,0\%); visita domiciliar $(0,6 \%)$, canil de isolamento $(0,5 \%)$; impossibilitada $(0,3 \%)$. Os resultados das observações foram: ignorado $(81,8 \%)$; sadio $(17,2 \%)$; sacrificado $(0,8 \%)$; doente $(0,1 \%)$; morto $(0,2 \% o)$. O encaminhamento do material colhido dos animais agressores para a confirmação laboratorial da raiva foi efetivado em $7,6 \%$ dos animais mortos.

O número de doses de vacina anti-rábica prescrito contemplou: ignorado $(35,2 \%)$; uma $(0,5 \%)$; duas $(0,2 \%)$; três $(5,9 \%)$; quatro $(1,5 \%)$; cinco $(17,9 \%)$; sete $(37,8 \%)$; dez $(1,0 \%)$. Os reforços adotados incluíram: ignorado $(64,8 \%)$; um $(0,2 \%)$; dois $(5,7 \%)$; três $(29,3 \%)$.

A condição do cumprimento do tratamento prescrito incluiu: ignorado (72,3\%); concluído $(20,3 \%)$; suspenso $(4,2 \%)$ e abandonado $(3,3 \%)$.

O campo destinado ao registro da ocorrência de complicações pós-vacinais não foi preenchido em $91,2 \%$ das fichas analisadas. Nas 321 fichas em que este campo foi preenchido há a informação de nove acidentes dos quais um de ordem neurológica. Os nove casos ocorreram em indivíduos que receberam sete ou mais doses de vacina.
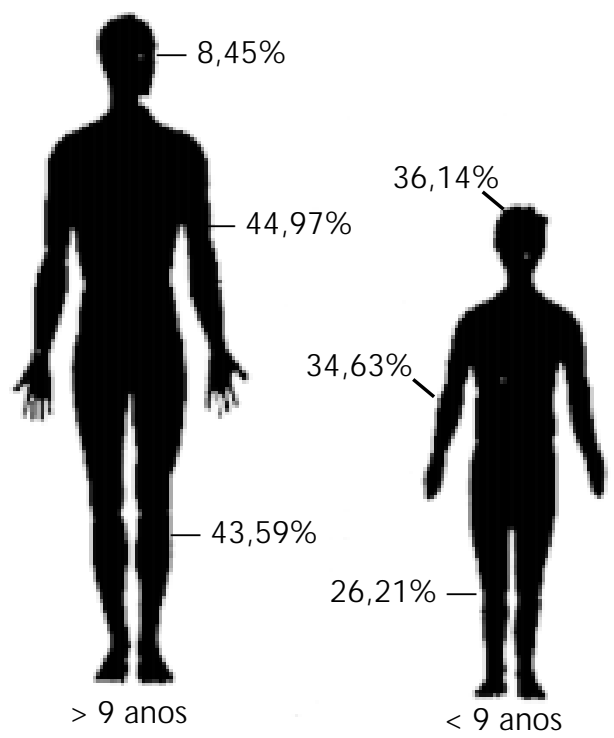

Figura 3 - Localização das sedes das lesões combinadas com a faixa etária dos pacientes agredidos. 
A distribuição cronológica dos tratamentos efetuados apresentou maior concentração nos anos de $1987(12,2 \%)$; $1988(12,0 \%)$ e $1992(11,2 \%)$. Nos outros anos a proporção, anual, de tratamentos instituídos situou-se entre $6,8 \%$ a $9,2 \%$. A distribuição mensal dos tratamentos apresentou concentrações nos meses de março $(9,6 \%)$, julho $(10,2 \%)$, agosto $(10,2 \%)$ e setembro $(9,7 \%)$, nos outros meses a proporção de atendimentos situou-se individualmente entre $7,1 \%$ a $8,6 \%$. A análise do período em cada mês com maior concentração de atendimentos revela maior concentração na primeira quinzena $(57,1 \%)$, com picos nos dias cinco $(4,3 \%)$; sete $(4,4 \%)$; oito $(4.4 \%)$; dez $(4,3 \%)$ e onze $(4,2 \%)$.

A observação da localização espacial dos casos atendido revelou que dos 57 bairros em que o município é dividido, houve 14 (24,6\%) onde não ocorreu nenhum registro de habitante agredido por animal durante os dez anos estudados. Dos 43 bairros com registros de casos, três, com maior concentração de população foram os mais acometidos: Novo Osasco (414); Helena Maria (396) e Bela Vista (386).

\section{DISCU SSÃO}

O preenchimento incompleto dos campos existentes nas fichas de tratamentos anti-rábicos, encontrado na presente investigação, também foi verificado em análise semelhante relativa a casos atendidos em cidades do interior do Estado de São Paulo (Marília, Assis e Tupã) ${ }^{11}$.

Em mais de dez itens do presente trabalho, a frequiência de campos não preenchidos ultrapassou $18 \%$. Os aspectos com maior percentual de falha no preenchimento (superior a 60\%) foram o tipo de observação adotada, o resultado da observação animal, o número de reforços vacinais aplicados, a evolução da vacinação, os acidentes vacinais e o local da vacinação. Esta constatação destaca a necessidade da mobilização de esforços para treinamento e reciclagem permanente das equipes de saúde pública para que os Serviços cumpram adequadamente o seu papel em termos de vigilância epidemiológica.

A coincidência observada de maior risco de exposição em faixas etárias inferiores a 15 anos e em indivíduos do sexo masculino pode ser explicada pela atividade mais intensa desses extratos, com maiores oportunidades de encontro com os animais, além de brincadeiras e de algumas atitudes bruscas que pudessem despertar reação agressiva do animal. O envolvimento de extratos populacionais semelhantes foi verificado em outros estudos realizados no Brasil $^{6,8,9,11}$ e no exterior ${ }^{7,16}$.

A localização da ocorrência das agressões incluiu $22,3 \%$ nas vias públicas e $46,8 \%$ no próprio domicílio da vítima. Este valor em localização domiciliar, muito próximo ao obtido no Município de São Paulo $(43,8 \%)^{9}$ é inferior ao observado em três municípios do interior do Estado de São Paulo $(65,7 \%)^{11}$. Estas constatações reforçam a importância da implantação permanente de programas educativos que promovam a posse responsável e o conhecimento dos cuidados que o homem deve dedicar aos seus animais de companhia.

O predomínio da participação do cão como animal agressor $(52,3 \%)$ concorda com outras avaliações já efetuadas, cujas proporções foram mais elevadas $(92,8 \%)^{8}$ : $(89,0 \%)^{9}$; e $(84,1 \%)^{11}$. Talvez esta diferença possa ser creditada ao grande número de fichas, da presente investigação, em que não houve o preenchimento em $35,6 \%$ do campo específico para este item.

A grande parcela de animais agressores não imunizados: $48,1 \%$ dos cães e $66,0 \%$ dos gatos, já havia sido encontrada em Belo Horizonte, $\mathbf{M G}^{8}$, e destaca a necessidade do reforço das atividades de educação em saúde que levem à conscientização da comunidade para a necessidade da vacinação anti-rábica anual dos animais de estimação.

$\mathrm{O}$ grande número de dispensas de tratamentos, com base na constatação de que o estado clínico dos animais agressores era sadio $(47,8 \%)$, destaca o papel assumido pela avaliação clínica dos animais agressores visando a reduzir a freqüência da instituição de vacinações em seres humanos.

O tipo de exposição mais freqüente foi a mordedura: 8.222 casos $(93,9 \%)$, seguida da arranhadura, 475 casos $(5,4 \%)$. É provável que a concentração de mordeduras deva-se ao fato de já existir uma conscientização da população de que este tipo de exposição envolve grande risco de contaminação pelo vírus da raiva, o que não acontece no caso de arranhaduras, lambeduras ou o simples contato.

$\mathrm{O}$ encontro de maior freqüência de lesões nos membros superiores $(40,9 \%)$ e cabeça $(19,4 \%)$, aliado ao fato de que a maioria dos casos ocorreu no 
próprio domicílio, pode ser explicado pela grande manipulação a que os animais de companhia são submetidos.

A análise das relações existentes entre a idade dos pacientes e a sede das lesões caracterizou o grupo com idade menor ou igual a nove anos como o mais envolvido $(39,3 \%)$ e no qual houve maior freqüência de lesões localizadas na cabeça, o que é esperado em função da estatura e da forma peculiar de relacionamento com os animais.

A grande freqüência de relato do tratamento imediato dos ferimentos com anti-sépticos ou apenas pela lavagem com água e sabão $(83,1 \%)$ é um indicador de uma conduta já conscientizada e que possui importante efeito na prevenção da doença ${ }^{18}$. Da mesma forma a rapidez com que os pacientes procuraram o Serviço de Profilaxia da Raiva, 88,57\% em até cinco dias, é outro indicador do bom nível de conscientização da comunidade local sob o risco da infecção ser contraída.

A freqüência encontrada para abandono aos tratamentos, $3,4 \%$ é inferior ao verificado em outras investigações: $(10,8 \%)^{6} ;(23,6 \%)^{8} ;(17,2 \%)^{9} ;(10,4 \%)^{11}$ e sugere, novamente, haver maior nível de conscientização da comunidade.

O tratamento pós-exposição prescrito dependia principalmente da espécie do animal agressor, tipo da lesão, e, no caso de cães e gatos, da possibilidade da observação. No caso de indicação de tratamento com vacinas, a precrição poderia ser de três doses de vacinas em dias alternados, sete doses de vacinas mais dois reforços ou aplicação de soro mais dez doses de vacinas e três reforços.

O campo relativo ao número de doses de vacinas aplicadas não foi preenchido em 1.277 fichas $(35,2 \%)$; 1.373 pacientes $(37,8 \%)$ receberam sete doses de vacina e $1.065(29,3 \%)$ receberam três reforços. Os nove casos de acidentes pós vacinais, dos quais um de ordem neurológica, ocorreram em indivíduos que receberam sete ou mais doses de vacina. Esta proporção difere da verificada em outros estudos, durante os períodos de 1976 a $1978^{6}$ (1: 24.568), para todos os tipos de complicações, e de 1980 a $1990^{15}$ (1:34.533) para as que acometeram o sistema nervoso central, reforçando a necessidade de que o tratamento antirábico, pós-exposição, seja instituído apenas quando exista uma justificativa consistente.

A maior freqüência das agressões ocorreu nos bairros do Município de Osasco que apresentaram maior densidade demográfica humana, o que é esperado, uma vez que o incremento da população canina é diretamente proporcional ao verificado na população humana. Do ponto de vista preventivo e buscando-se a permanente redução do número de pessoas submetidas ao tratamento anti-rábico, pós-exposição, as áreas mais atingidas deveriam ser objeto de uma maior preocupação das autoridades locais com vistas ao planejamento de uma estratégia específica de educação em saúde.

\section{REFERÊNCIAS}

1. Bauer HA. A guide for laboratory diagnosis and post exposure treatment of rabies. Archs Envir Health 1969; 19:868-70

2. Corey L, Hattwick MAW. Treatment of persons exposed to rabies. J Am Med Assoc 1975; 232:272.

3. Cox HR. Rabies: laboratory diagnosis and post exposure treatment. Am J Clin Pathol 1972; 57:794-802.

4. Dean AG, Dean JA, CoulombIer D, Burton A H, Brendel KA, Smith DC, Dicker RC, Sulivan KM, Fragan RF. Epi Info, version 6: a word processing, data base and statistics program for epidemiology on microcomputers. Atlanta, [computer program]: Centers for Disease Control and Prevention; 1994.

5. Fuenazalida E. Consideraciones sobre la vacuna en cerebro de ratón lactante. Salud Pública Méx 1974; 16:443-50.
6. Gomes FJP. Programa nacional de profilaxia da raiva: considerações sobre o seu desenvolvimento, 1975-1978. In: $3^{\circ}$ Seminário sobre Técnicas de Controle da Raiva; 1979; São Paulo. São Paulo: Secretaria de Estado da Saúde 1979; p. 41-53.

7. Helmick CG. The epidemiology of human rabies postexposure prophilaxis, 1980-1981. J Am MedAssoc 1983; 250:1990-6

8. Moreira EC, Gontijo AC, Reis R, Viana FC, Moreira WL. Aspectos epidemiológicos del tratamiento anti-rábico humano en Belo Horizonte, Minas Gerais, Brasil. Bol Oficina Sanit Panam 1976; 80:38-44.

9. Ribeiro Netto A, Machado CG. Alguns aspectos epidemiológicos da exposição humana ao risco da infecção pelo vírus da raiva, na cidade de São Paulo, Brasil. Rev Inst Med Trop São Paulo 1970; 12:16-30. 
10. Pinto CL, Alleoni ES. Aspectos da vigilância epidemiológica da raiva em sub-regiões admnistrativas do Estado de São Paulo, Brasil, 1982-1983. Rev Saúde Pública 1986; 20:288-92.

11. Prefeitura Municipal de Osasco. Secretaria de Obras. Departamento de Projetos Urbanos. Projeção da população humana de Osasco para 1995. Osasco; 1995.

12. Schneider MC, Almeida GA, Souza LM, Morares NB. Controle da raiva no Brasil de 1980 a 1990. Rev Saúde Pública 1996; 30:196-203.

13. Secretaria de Estado da Saúde. Departamento Técnico Normativo. Divisão de Normas Técnicas. Norma técnica SS 26/81: tratamento preventivo da raiva humana: aprovada em 19/05/81. São Paulo; 1981.

14. Secretaria de Estado da Saúde. Departamento Técnico Normativo. Divisão de Normas Técnicas. Anexo à Norma Técnica SS 26/81 - SP: imunização preventiva da raiva humana [uso exclusivo no Município de São Paulo; aprovada em 29/04/85]. São Paulo; 1985.
15. Secretaria de Estado da Saúde. Centro de Vigilância Epidemiológica. Norma técnica SS 1/88: tratamento preventivo anti-rábico humano. São Paulo; 1988 [aprovada em 11/11/88].

16. Szyfres L, Arrossi JC, Marchevsky N. Rabia urbana: el problema de las lesiones por mordedura de perro. Bol Oficina Sanit Panam 1982; 92:310-27.

17. Vasconcellos SA, Côrtes JA, Nilson MR, Ito FH, Enriquez Rozas CE. Diagnóstico "in vivo" da raiva em cães. Emprego do teste de córnea e isolamento de vírus pela inoculação intracerebral de saliva em camundongos. Rev Fac Med Vet Zootec. Univ S Paulo $1978 ; 15: 75-86$.

18. World Health Organization. Comite de expertos en rabia. Geneva; 1960. (Technical Report on Rabies, 201). 